\title{
Clinical evaluation of a water-in-oil emulsion with protective and regenerative properties for the anogenital area
}

This article was published in the following Dove Press journal:

Clinical, Cosmetic and Investigational Dermatology

4 November 2015

Number of times this article has been viewed

\author{
Volkmar Küppers' \\ Michael Kemper ${ }^{2}$ \\ Christoph Abels ${ }^{2}$ \\ 'Gynecological Practice, Dysplasia- \\ Clinic, Düsseldorf, Germany; \\ ${ }^{2}$ Dr August Wolff GmbH \& Co KG \\ Arzneimittel, Bielefeld, Germany
}

Correspondence: Christoph Abels Dr August Wolff GmbH \& Co KG Arzneimittel, Sudbrackstrasse 56, 336II Bielefeld, Germany Email christoph.abels@wolff-arzneimittel.de
Abstract: Inadequate hygiene, aggressive cleansing, and chafing skin folds, as well as urine, feces, and sweat may trigger irritative contact dermatitis in the anogenital area. Serious recommendations for protection of the skin toward irritants include hygienic aspects and the use of appropriate skin care. Furthermore, preventing an accumulation of irritants on unprotected skin is mandatory. An intraindividual comparison study with 30 participants (17 female, 13 male; age: $44.2 \pm 8.3$ years) was performed to evaluate the properties of a newly developed water-inoil (W/O) balm on artificial sodium dodecyl sulfate-damaged epidermal barrier. The balm was applied 14 days twice daily, and transepidermal water loss and erythema were investigated. A significant improvement of both parameters after 12 days and even after 21 days could be confirmed. Two major clinical trials were performed to evaluate the safety and efficacy regarding protective and regenerative properties of the $\mathrm{W} / \mathrm{O}$ balm on irritated skin in the anogenital area. Therefore, 29 children were enrolled (14 male, 15 female, age: $15.5 \pm 7.8$ months) in an openlabeled 4-week clinical study. The balm was used in the area under disposable diapers at least after diaper change or if required. Furthermore, in a second open, multicenter study, 43 women (mean age: $46.2 \pm 16.9$ ) with predisposition to skin irritation in the outer anogenital region were included. The product was applied for 4 weeks 1-2 times daily. In both studies, skin tolerability, applicability, scent, spreadability, and removability of the balm were evaluated by participants and practitioners predominantly as good or even very good, also skin hydration, protection, and regeneration were judged positively. The studies confirmed that the newly developed W/O balm exhibits excellent tolerability and is easy to remove. At the same time, excellent properties with respect to efficacy regarding regeneration and protection could be observed, without any undesired effects at any time.

Keywords: intimate care, diaper rash, dermatitis, epidermal barrier

\section{Introduction}

In general, irritant contact dermatitis directly affects the barrier properties of the epidermis. ${ }^{1}$ This results in an inflammatory nonimmunologic cutaneous reaction. ${ }^{2}$ The clinical spectrum ranges from erythema, slight scaling, edema, and erosions to eczematous conditions. ${ }^{3}$

The resulting imbalances of immune regulators cause painful skin erosion, which is the basis for skin infections. ${ }^{4,5}$ The initial trigger factors are physical irritants such as sweat, inadequate hygiene, aggressive cleansing, and chafing skin folds, as well as chemical irritants such as urine, feces, and sweat, which remain in skin folds. Indeed, irritant contact dermatitis is common for the early childhood, ${ }^{6-8}$ but it also occurs in the elderly because of an impaired skin barrier, increased skin folds, and frequent incontinence accompanied with accumulation of urine and feces. ${ }^{9,10}$ 
Furthermore, high physical activity, for example, biking, horse riding, and marathon running, may also predispose for skin irritation, mainly in the anogenital area. ${ }^{11,12}$ Other typical areas prone to skin irritation are regions of the body where skin folds chafe on each other like the regions under the breasts and the umbilicus but also the axillae and the skin between the digits. ${ }^{13}$

Recommendations for protection against development of an irritant contact dermatitis in the anogenital area aim not only on reducing contact with the irritants, but also hygienic aspects such as keeping the folds dry and using appropriate skin care. ${ }^{14}$ Skin care products should be designed as sufficient water-in-oil (W/O) formulations. ${ }^{15} \mathrm{~W} / \mathrm{O}$ emulsions protect the skin toward outside irritants but without occlusion to allow for evaporation of water from inside. ${ }^{16}$ Waterfree, mineral oil-based products should be avoided because they may damage the epidermal barrier by creating occlusive conditions and may even promote secondary infections or foster skin irritation. ${ }^{17-20}$ Unfortunately, traditional protective lipophilic creams, for example, for baby care or the intimate area, are mostly based on mineral oils and often contain zinc oxide, ${ }^{21}$ which generates a hard to remove occlusive film and covers the skin tightly.22

Taking these recommendations into account, a skin protecting only slightly occlusive W/O balm was developed and clinically evaluated, which is suitable for the anogenital area and all intertriginous regions of women and men and for daily care of the nappy areas of babies as well.

\section{Materials and methods}

The clinical studies were performed according to the requirements of the Declaration of Helsinki and were approved by the relevant ethical committees $(013 / 1133,013 / 1238$, $013 / 1084$ ) and registered in the german register for clinical trials (Deutsche Register Klinischer Studien) with following IDs: DRKS00009497, DRKS00009503 and DRKS00009504. According to that, all subjects or parents/legal guardians have given consent to the studies in written form.

\section{Cosmetical formulation}

The cosmetic product Linola ${ }^{\circledR}$ protective balm was used. The balm is a W/O emulsion consisting of caprylic/capric triglyceride, cocoglycerides, aqua, octyldodecyl myristate, oleyl erucate, Acacia decurrens/jojoba/sunflower seed cera/ polyglyceryl-3 esters, glyceryl stearate, hydrogenated castor oil, glyceryl dibehenate, glyceryl behenate, tribehenin, benzyl alcohol, butylene glycol, pentylene glycol, octenidine $\mathrm{HCl}$, hydroxyphenyl propamidobenzoic acid, Zingiber officinale root extract, bisabolol, and ascorbyl palmitate.

\section{Clinical study to assess protection and regeneration after SDS-induced skin irritation in healthy volunteers} Study design

An artificial irritation of the skin by sodium dodecyl sulfate (SDS) was performed to mimic epidermal barrier damage and to evaluate the regenerative and protective properties of Linola ${ }^{\circledR}$ protective balm. Thirty participants (17 female, 13 male; age: $44.2 \pm 8.3$ years) were included in this intraindividual comparison study. The product was applied on the inner forearm for 14 days twice daily. Testing parameters were skin hydration (Corneometer MPA 5 CPU), transepidermal water loss (TEWL) (Tewameter TM 210), skin redness (Chromameter SN C 8202118), and skin roughness (PRIMOS compact high-res S/N 108-00042). Untreated skin areas served as control.

\section{Study design}

During days 1-7, the test area had to be washed once daily with 5\% SDS solution to induce an artificial irritation of the skin. At day 8 , the test parameters were measured. During the second phase (regeneration phase) from days 9 to 14 , the test product was applied twice daily and regenerative product properties were measured 12-14 hours after the application on days 10, 12, and 15. From days 15 to 21 (protection phase), the protective product properties were evaluated. For this purpose, the participants were asked to continue the product application procedure twice daily, but to additionally wash the testing area with 5\% SDS solution 1 hour after each product application. Measurements were taken 5- 6 hours after product application and washing in the morning on days 17,19 , and 21 .

\section{Clinical study to assess protection from diaper rash in babies and toddlers Study design}

A total of 29 children were enrolled (14 male, 15 female; age: $15.5 \pm 7.8$ months) in this open-labeled clinical study. The test product was used in the area under disposable diapers at least after each diaper change and even more often if required, according to the respective needs and normal using habits. The duration of treatment was 4 weeks. At the beginning, as well as after 4 weeks of treatment, erythema, dryness, scaling, fissures, papules, pustules, edema, vesicles, and weeping were assessed as objective parameters by a pediatrician. Subjective assessment of product properties was performed by subject questionnaire. Active skin diseases at the test area, such as acute diaper dermatitis, by not using 
the diaper during the day and night due to potty training or other reasons were excluded.

\section{Study execution}

A dermatological examination of the skin in the test area was performed by a pediatrician prior to start of the trial. The parents/legal guardians of the children were instructed to use the test product at least after each diaper change and even more often if required, according to the babies' needs and their normal using habits. The parents/legal guardians continued to use the normally used cleansing products for their participating children. The test product was applied for 4 weeks. After 28 days, the parents/legal guardians were asked to complete a questionnaire. Again, the pediatrician performed a dermatological examination of the skin in the test area. The objective test parameters were erythema, dryness, scaling, fissures, papules, pustules, edema, vesicles, weeping, other, which were evaluated on a numerical scale between 0 and $3(0=$ no result, $1=$ slight, $2=$ moderate, $3=$ severe $)$. Adverse effects were noted.

\section{Clinical study to assess efficacy and tolerability in the anogenital area of women suffering from skin irritation}

\section{Study design}

In an open, multicenter study in 2013, 43 women (mean age: $46.2 \pm 16.9)$ with predisposition to skin irritation in the outer anogenital region were included. The product was applied to the outer anogenital area for 28 days one to two times daily, at least after every cleansing. Testing parameters monitored during the study were skin tolerability and efficacy (skin care and protection). Product properties of Linola $^{\circledR}$ protective balm were assessed subjectively by the volunteers according to a questionnaire. Women with skin infection, skin erosion, neoplasia, skin diseases, pregnancy, or hypersensitivity against one of the ingredients as well as women in or after radiotherapy or simultaneous application of another skin protection product were excluded from the study.

\section{Study execution}

Before starting the study (visit 1), a physician took demographic data, diseases, and "risk factors" for skin irritations, such as excessive sports and excessive sweating, overwashing of the intimate area, urine and/or fecal incontinence, or tight clothing. In addition, the date of beginning of the irritation of each participant was documented. Women were asked to answer a questionnaire concerning the severity of their complaints such as excoriation, burning, stinging and itching, roughness, and swelling and to evaluate their subjective symptoms. The symptoms were graded by a 4 -scale score $(0=$ not existing, $1=$ slight, $2=$ moderate, $3=$ severe). Moreover, an objective assessment of their symptoms was performed by a physician. Therefore, skin glow, itching, and hyperkeratosis were graded using a 4 -scale score $(0=$ not existing, $1=$ slight, $2=$ moderate, $3=$ severe) .

During the study, the women were asked to document frequency of application and risk factors. Furthermore, on a weekly basis they graded their subjective complaints and noted undesired effects according to cosmetic regulation $1223 / 2009 / \mathrm{EG}$ and other products they had applied in this time. At the end of the study, a final objective assessment of the symptoms was performed (visit 2).

\section{Results \\ Clinical study to assess protection and regeneration after SDS-induced skin irritation in healthy volunteers}

After 8 days of skin irritation with 5\% SDS solution, TEWL increased to $5.6 \pm 3.7,6 \pm 3.5 \mathrm{~g} / \mathrm{h} \mathrm{m} \mathrm{m}^{2}$, respectively (Figure 1A). After the regeneration phase from days 8 to 15 , the untreated irritated area exhibited a TEWL of $1.5 \pm 1.7 \mathrm{~g} / \mathrm{h} \mathrm{m}^{2}$, whereas the treated area exhibited a TEWL of $0.7 \pm 1.7 \mathrm{~g} / \mathrm{h} \mathrm{m}^{2}$ at day $8(P<0.05)$. After the protection phase on day 21, TEWL increased again due to SDS irritation in the untreated area to $5.6 \pm 3.2 \mathrm{~g} / \mathrm{h} \mathrm{m}^{2}$, whereas in the treated area, a TEWL of $3.37 \pm 2.5 \mathrm{~g} / \mathrm{h} \mathrm{m}^{2}$ was measured $(P<0.05)$ (Figure 1A).

Erythema increased up to day 8 to $1.57 \pm 1.32$ au and $1.74 \pm 1.25 \mathrm{au}$, respectively. During the regeneration phase, erythema decreased in the untreated irritated area $(0.59 \pm 1.01 \mathrm{au})$ and in the treated area $(0.21 \pm 0.81 \mathrm{au})$. The difference was statistically significant $(P<0.05)$. After the protection phase, erythema increased again (1.71 1.89 au in untreated and $1.03 \pm 1.53$ au in treated area). The increase in the treated area was statistically significantly lower $(P<0.05)$ (Figure 1B).

\section{Clinical study to assess protection from diaper rash in babies and toddlers}

In this study, parents/legal guardians applied the balm 3-4 times daily in 58.6\% and even $>4$ times daily in $41.4 \%$ of all cases. Dermatological evaluation at baseline revealed findings in $62.5 \%$ of the babies: very mild papules in $25 \%$, very mild erythema in $31 \%$, and a mild erythema in $3 \%$ of the babies. After 4 weeks of application, only $12.5 \%$ of the 

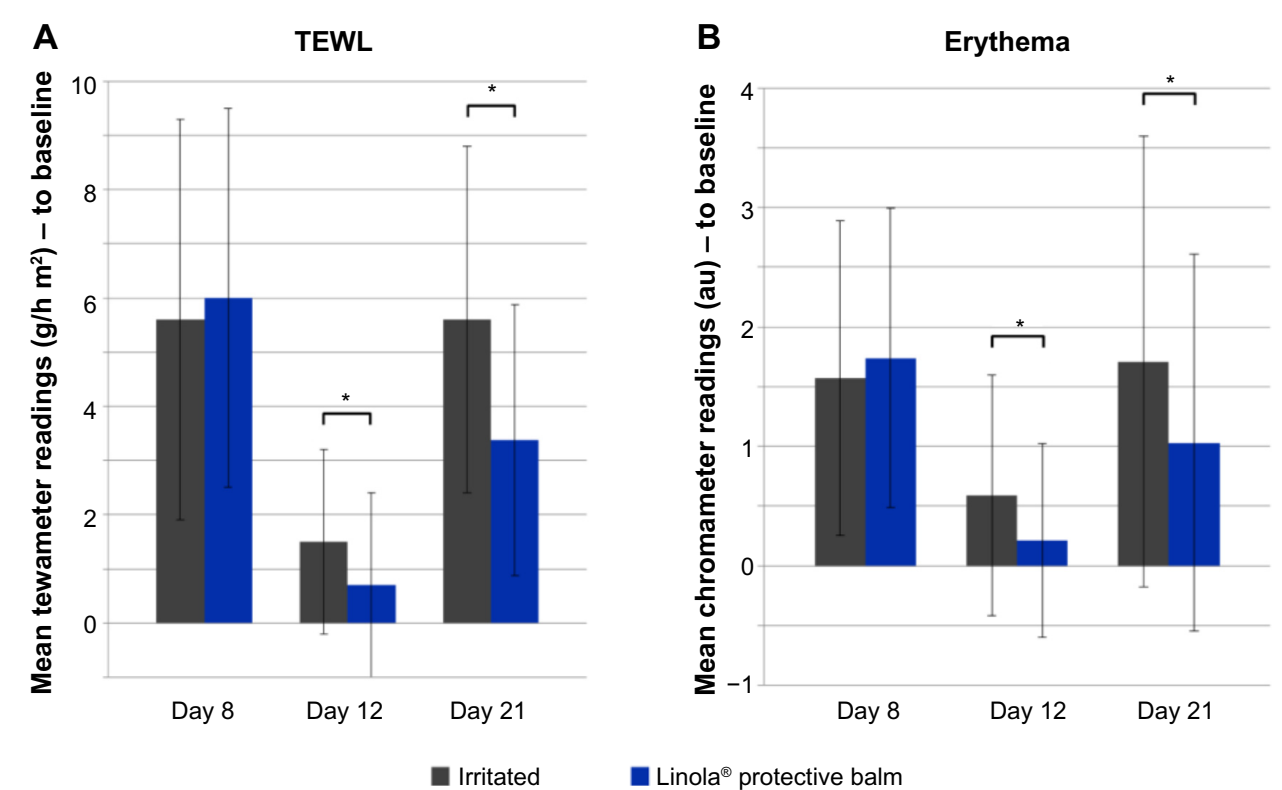

Figure I Regenerative and protective properties of Linola ${ }^{\circledR}$ protective balm.

Notes: Regenerative and protective properties of Linola ${ }^{\circledR}$ protective balm were assessed in a trial with 30 individuals ( 17 female, 13 male; age, $44.2 \pm 8.3$ years). The figure elucidates the study design. Baseline measurements were performed on day I. Until day 8 , irritation of the skin was induced by daily application of $5 \%$ SDS solution. In the second phase (regeneration), Linola ${ }^{\circledR}$ protective balm was applied twice daily to the irritated skin up to day I5 to evaluate the regenerative properties of the product. Skin measurements were performed on days $8,10,12,15,17,19$, and 21 . During the protection phase, Linola ${ }^{\circledR}$ protective balm and $5 \%$ SDS were daily applied consecutively, and the outcome was measured on day 2 I. (A and B) TEWL and erythema were measured with and without application of Linola ${ }^{\circledR}$ protective balm on the skin during regeneration phase and at the end of protection phase. Mean $\pm S D ; * P<0.05$ in Wilcoxon rank test.

Abbreviations: SDS, sodium dodecyl sulfate; TEWL, transepidermal water loss; SD, standard deviation.

babies showed findings upon dermatological evaluation: very mild erythema in only $9 \%$ and moderate papules in only $3 \%$ of the babies (Figure 2).

The subjective evaluation by the parents/legal guardians showed in $69 \%$ a very good spreadability of the balm. Furthermore, $69 \%$ documented a better removability of the balm compared to the previously used products. Overall, the majority of the parents/legal guardians were satisfied with the balm. Approximately $75.9 \%$ of the parents/legal guardians confirmed that they would like to continue the usage of the test product for the diaper area of their babies.

One adverse reaction occurred with possible relation to the test product in terms of papules with moderate severity in the diaper area.

\section{Clinical study to assess efficacy and tolerability in the anogenital area of women suffering from skin irritation}

In this study, $73.8 \%$ of the women suffered from symptoms $>6$ months with a permanent manifestation in $69 \%$ of all cases.

The sum score of the single complaints (excoriation, burning, stinging and itching, roughness, swelling, and itching) was $11.4 \pm 2.7$ at the beginning. During the application of Linola ${ }^{\circledR}$ protective balm, a statistically significant decline was observed (week 1: $8.0 \pm 4.0$; week 2: 6.1 \pm 4.3 ; week 3: 4.7 \pm 4.3; week 4: 4.4 \pm 4.8$)(P<0.0001)$ (Figure 3A). After the first week, already $81 \%$ of the test persons felt an improvement of their complaints, further increasing up to $90.5 \%$ after week 2 and $92.9 \%$ after weeks 3 and 4 . A more detailed view on the results of the evaluation of single complaints (excoriation, burning, stinging and itching, roughness, swelling, and itching) revealed an ongoing decline of all complaints. The improvement toward baseline was statistically significant for all complaints $(P<0.05)$, except stinging after week 1 (Figure 3B). Furthermore, the proportion of subjects in which objective symptoms, evaluated by a gynecologist, were no longer present decreased from visit 1 to visit 2 by at least $14 \%$. The proportion of women without erythema increased from $28.6 \%$ to $42.9 \%$, without skin glow from $45.2 \%$ to $66.7 \%$, and without swelling from $50 \%$ to $73.8 \%$. Overall, a gynecologist evaluated the global tolerability for $61.9 \%$ of the subjects as very good and good for $35.7 \%$, and the efficacy was evaluated as good or even very good for $80.9 \%$ of the subjects, which is statistically significant compared to baseline.

Moreover, the number of women without any symptom increased with increasing length of the study. Comparing visit 1 (at the beginning of the study) and visit 2 (at the end of the study), the proportion of women without itching increased from $2.4 \%$ up to $47.6 \%$, without excoriations from 


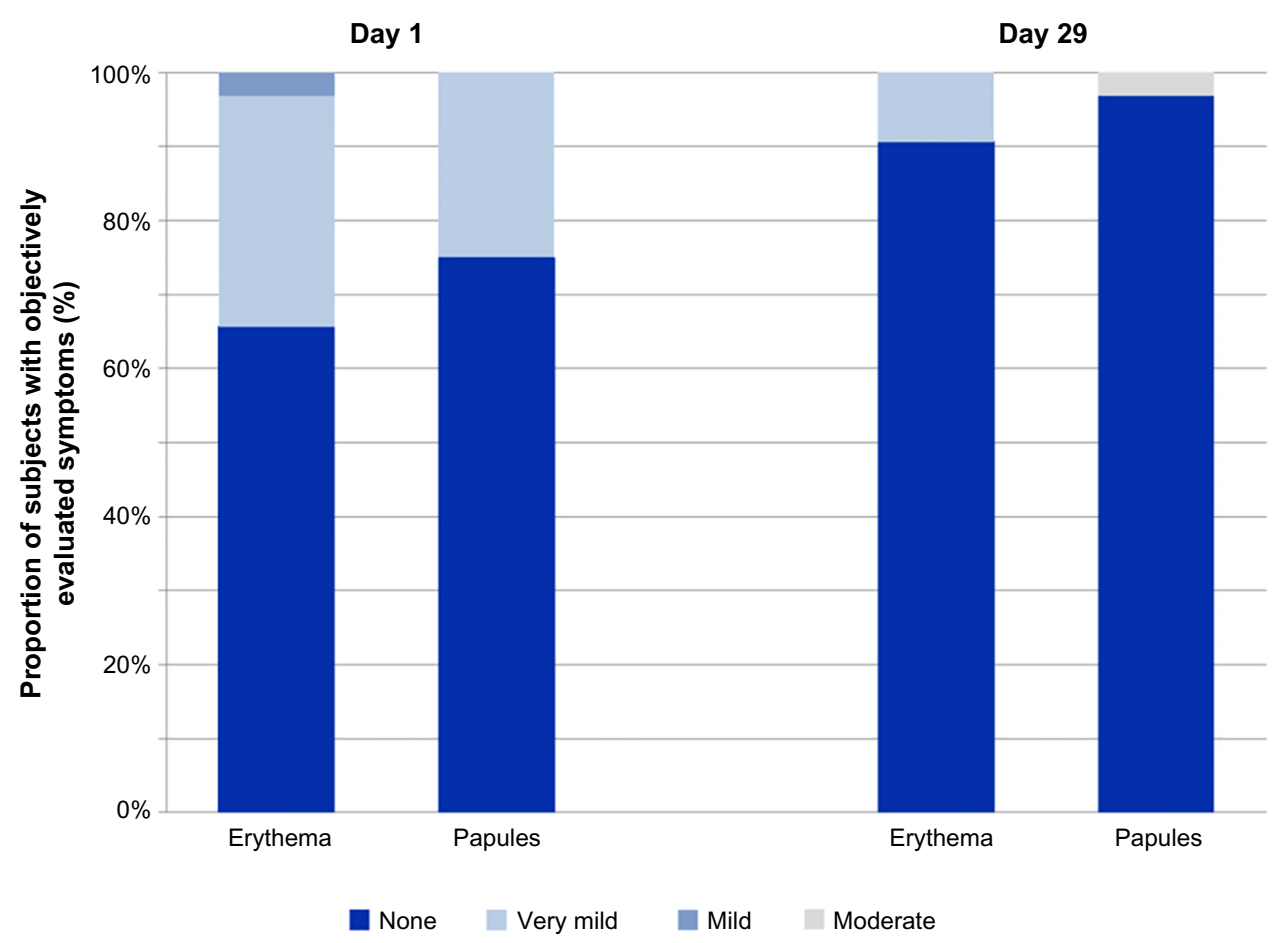

Figure 2 Results of an application trial in the diaper area.

Notes: Thirty-nine babies (I5 female, 14 male; age, 15.5 \pm 7.8 months [mean \pm SD]) were enrolled in a trial to evaluate skin tolerability and cosmetic acceptance of Linola ${ }^{\circledR}$ protective balm. On day I and day 29, the diaper area of the subjects was dermatologically evaluated by a pediatrician regarding erythema and papules with a 5 -scale score of severity $\left(0=\right.$ no result, $0.5=$ very slight, $I=$ slight, $2=$ moderate, $3=$ strong). Treatment with Linola ${ }^{\circledR}$ protective balm reduced number of subjects with mentioned complaints.

$4.8 \%$ to $45.2 \%$, without burning from $7.1 \%$ up to $52.4 \%$, without feeling of roughness from $23.8 \%$ to $64.3 \%$, without swelling from $26.2 \%$ to $59.5 \%$, and without stinging from $31 \%$ to $64.3 \%$.

The Protective Balm was assessed as good (gynecologist: 52.4\%; women: $47.6 \%$ ) or very good (gynecologist: $35.7 \%$; women: $19.0 \%$ ) for all enquired items. During the 4 weeks application study, no severe adverse events were observed at any time.

\section{Discussion}

Unfortunately, no general recommendations regarding skin care for the regeneration of and protection of the intimate area from irritant contact dermatitis and intertriginous skin
A

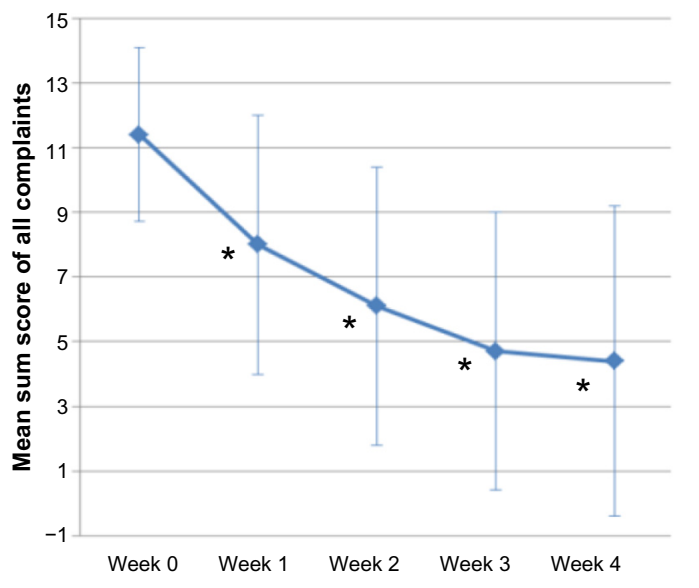

B

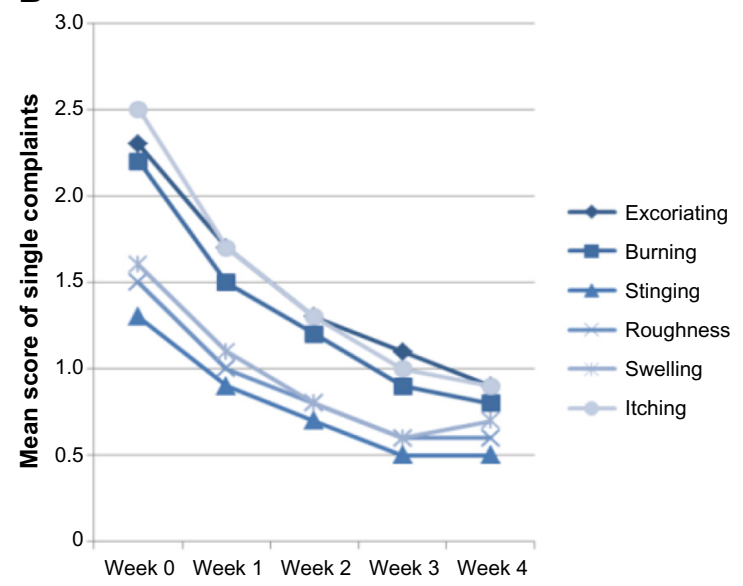

Figure 3 Results of an application trial to test the efficacy and skin tolerability of Linola ${ }^{\circledR}$.

Notes: Protective balm, performed with 43 women (46.2 \pm 16.9 years) prone to skin irritation in the outer intimate region. (A) Single complaints were pooled to a mean sum score of all complaints and reveal a consistent statistically significant decline. Mean; $* P<0.000$ I in Wilcoxon rank test. (B) During the application, mean scores of single complaints (eg, burning, roughness, and itching) were assessed. Use of Linola ${ }^{\circledR}$ protective balm led to a reduction of all complaints. An ongoing decline in the complaints could be observed weekly. The improvements toward baseline (week I) were statistically significant, excluding stinging after week I. Mean \pm SD; $* P<0.05$ in Wilcoxon rank test. 
lesions are available, and studies are still lacking. Only guidelines for skin care related to urinary and fecal incontinence are published. ${ }^{19,23}$ Since these are trigger factors for irritant contact dermatitis in the anogenital area, as sports or overwashing are likewise, the recommendations can be extended for other irritants and generalized - with some limitations - for all ages (eg, babies and elderly). Since all physical and chemical irritants damage the epidermal barrier, ${ }^{1}$ the maintenance of this barrier should be the main goal of appropriate skin care. Appropriate W/O emulsions are preferred because of minor occlusive but at the same time protecting properties. In contrast, waterfree, mineral oil-based products should be avoided because they may damage the epidermal barrier, create occlusive conditions, and may even promote secondary infections or foster skin irritation. ${ }^{16,18-20}$ Unfortunately, still today, most intimate care products are mineral oil based, and even in daily baby care, the use of occlusive, hard to remove pastes or ointments is still common. On the one hand, the formulations have to protect against moisture, on the other hand, the skin care product has to permit water to evaporate because the skin should not be covered too tightly. ${ }^{16}$ Therefore, the new W/O balm was developed with minor occlusive properties and compared to a common mineral oil-based intimate care product. A simple experiment was performed and exhibited minor occlusive effect for the balm compared to the mineral oil-based product (data not shown).

In general, the development of intimate care products should focus on the composition of the formulation ${ }^{24}$ since intravaginal traces of the applied products cannot be excluded. Just recently, in multivariable analysis, women reporting the intravaginal use of petroleum jelly are significantly more likely to test positive for bacterial vaginosis. ${ }^{25}$ Therefore, the use of petroleum jelly (vaseline, petrolatum) containing products in the anogenital area should be reconsidered. Utilizing plant-derived lipids to formulate a $\mathrm{W} / \mathrm{O}$ emulsion with mild occlusive properties, the balm was developed to protect against moisture and other irritative influences and being suitable for long-term use because intimate care products should not only be used to prevent friction from skin folds or diapers, but also to protect the skin from contact with moisture and other chemical irritants in the long term. ${ }^{26}$ In general, mild emulsifiers and humectants used as ingredients in the balm lead to a transparent, water repellent, and long-lasting film on the skin, which not only protects the skin against irritants but also simplifies their removal. Furthermore, appropriate clinical tests with respect to excellent tolerability are important, ${ }^{27,28}$ especially incontinence-associated dermatitis (IAD) is a preventable condition, whereby persistent skin contact with urine, feces, and sweat leads to skin irritation. IAD has a complex pathogenesis and is a form of moisture-associated dermatitis, aggravated by occlusion and maceration that produces erythema, inflammation, and eventual loss of skin integrity. ${ }^{29,30}$ Therefore, initially an artificial irritation of the skin by SDS was performed to mimic mentioned characteristics of IAD. The properties of the balm were investigated by monitoring the improvement of TEWL and erythema. After 4 days of application, the balm improved TEWL and erythema significantly and provided first indications of the efficacy and tolerability of the balm.

The objective dermatological evaluation of the diaper area of the babies revealed a reduction of number of babies with complaints after 4 weeks of application of the balm. Only three babies suffered from erythema with very mild symptoms, whereas the number of subjects showing papules was reduced to one. However, all of the studies showed a very good skin tolerability of the balm. No serious adverse events were observed after application in the conducted clinical studies. The removability of the newly developed product was addressed in a study on babies and toddlers during 4 weeks of application. It was assessed in $69 \%$ of the parents/legal guardians as even better compared to previously used mostly zinc oxide-based products.

The objective assessment of the symptoms and abnormal findings, so-called secondary morphology, ${ }^{31}$ assessed by physicians provided specific evidence of the regenerative and protective properties of the balm in the main multicenter study with women predisposed to skin irritation in the outer anogenital region. The severity of erythema, skin glow, swelling, and hyperkeratosis declined significantly during 4 weeks. The subjective evaluation in the study by the women revealed also high efficacy for the newly developed balm. The severity of the subjective complaints decreased permanently for each single item such as excoriation, burning, stinging and itching, roughness, swelling, and itching.

\section{Conclusion}

In summary, the balm was developed as a nonirritating, water-repellent $\mathrm{W} / \mathrm{O}$ emulsion with low occlusive properties, without mineral oil, silicones, or zinc oxide, based on plant-derived lipids with anti-irritative compounds. The balm is suitable for the daily care in the intimate and anogential area and protects the skin from excessive moisture, which may cause irritative contact dermatitis. It regenerates the epidermal barrier damaged by irritative substances and is easy to apply and to remove. The efficacy regarding regenerative and protective properties, skin tolerability, and cosmetic 
acceptance of the balm was evaluated positively on babies and toddlers, as well as in women with predisposition to skin irritation in the outer intimate region.

\section{Acknowledgments}

The tested products were formulated according to the requirements by Dr August Wolff GmbH \& Co KG Arzneimittel. The study was designed by Dr August Wolff GmbH \& Co KG Arzneimittel and performed by Pharmalog, Derma Consult Concept $\mathrm{GmbH}$, and proDERM.

\section{Author contributions}

All authors contributed toward data analysis, drafting and critically revising the paper and agree to be accountable for all aspects of the work.

\section{Disclosure}

$\mathrm{CA}$ and MK are employees of Dr August Wolff Arzneimittel $\mathrm{GmbH} \& \mathrm{Co} \mathrm{KG}$ (sponsor of the studies). VK was the investigator of one clinical study. The authors report no other conflicts of interest in this work.

\section{References}

1. Mathias CG, Maibach HI. Dermatotoxicology monographs I. Cutaneous irritation: factors influencing the response to irritants. Clin Toxicol. 1978;13(3):333-346.

2. Tan $\mathrm{CH}$, Rasool S, Johnston GA. Contact dermatitis: allergic and irritant. Clin Dermatol. 2014;32:116-124.

3. Ale IS, Maibach HI. Irritant contact dermatitis. Rev Environ Health. 2014;29(3):195-206.

4. Yosipovitch G, Tur E, Cohen O, Rusecki Y. Skin surface pH in intertriginous areas in NIDDM patients. Possible correlation to candidal intertrigo. Diabetes Care. 1993;16:560-563.

5. Sibbald RG, Kelley J, Kennedy-Evans KL, Labrecque C, Waters N. Practical Approach to the Prevention and Management of Intertrigo, or Moisture-associated Skin Damage, Due to Perspiration: Expert Consensus on Best Practice. Vol 11. Canada: Wound Care Canada; 2013.

6. Braun-Falco O. Dermatology. Berlin Heidelberg: Springer-Verlag; 1996:466.

7. Honig PJ, Frieden IJ, Kim HJ, Yan AC. Streptococcal intertrigo: an under recognized condition in children. Pediatrics. 2003;112 (6 pt 1):1427-1429.

8. Lau K, Höger PH. Dermatologische Probleme bei Kindern mit Adipositas. Bundesgesundheitsblatt Gesundheitsforschung Gesundheitsschutz. 2013;56:539-542.

9. Farage MA, Miller KW, Berardesca E, Maibach HI. Incontinence in the aged: contact dermatitis and other cutaneous consequences. Contact Dermatitis. 2007;57(4):211-217.

10. Köther I. Altenpflege Professionell. Thiemes Altenpflege. Stuttgart: Georg Thieme Verlag, Auflage; 2007.

11. Derya A, Elgen E, Metin E. Characteristics of sports-related dermatoses for different types of sports: a cross-sectional study. J Dermatol. 2005;32:620-625.
12. Aneja S, Taylor JS. Skin disorders in athletes: professional and recreational sports. In: Aneja S, Taylor JS, editors. Kanerva's Occupational Dermatology. New York: Springer; 2012:1661-1678.

13. Lin JY, Shih YL, Ho HC. Foot bacterial intertrigo mimicking interdigital tinea pedis. Chang Gung Med J. 2011;34(1):44-49.

14. Mistiaen P, van Halm-Walters M. Prevention and treatment of intertrigo in large skin folds of adults: a systematic review. BMC Nurs. 2010;9:12.

15. Daniels R, Knie U. Galenik der Dermatika - Grundlagen, Eigenschaften, Freisetzung. JDDG. 2007;5(5):367-383.

16. Schäfer P, Bewick-Sonntag C, Berardesca E. Physiological changes in skin barrier function in relation to occlusion level, exposure time and climatic conditions. Skin Pharmacol Physiol. 2002;15(1):7-19.

17. Fluhr JW, Lazzerini S, Distante F, Gloor M, Berardesca E. Effects of prolonged occlusion on stratum corneum barrier function and water holding capacity. Skin Pharmacol Appl Skin Physiol. 1999;12: 193-198.

18. Fluhr J, Elsner P, Berardesca E, Maibach HI. Bioengineering of the Skin. Water and the Stratum Corneum. Dermatology: Clinical and Basics Science Series. 2nd ed. Florida: CRC Press; 2005.

19. Nashan D, Schumann H, Meis J, Kliesch S. Harninkontinenz: Übersicht zur Klinik, Prävention und Therapie dermatologischer Folgeerkrankungen. Available at: http://www.dkvg.de/download/inkontinenz.pdf, Australia: Handbuch Geriatrie, Deutsche Krankenhaus-Verlagsgesellschaft; 2005. German.

20. Van der Valk PGM, Maibach HI. Post-application occlusion substantially increases the irritant response of the skin to repeated short-term sodium lauryl sulfate (SLS) exposure. Contact Dermatitis. 1989;21(5):335-338.

21. Stamatas GN, Tierney NK. Diaper dermatitis: etiology, manifestations, prevention, and management. Pediatric Dermatology. 2014;31(1):1-7.

22. Williams DF, Schmitt WH. Chemistry and Technology of the Cosmetics and Toiletries Industry. 2nd ed. London: Chapman and Hall; 1996.

23. Gillibrand W. Faecal incontinence in the elderly: issues and interventions in the home. Br J Community Nurs. 2012;17(8):364-368.

24. Farage MA, Scheffler H. Assessing the dermal safety of products intended for genital mucosal exposure. Curr Probl Dermatol. 2011;40:116-124.

25. Brown JM, Hess KL, Brown S, Murphy C, Waldman AL, Hezareh M. Intravaginal practices and risk of bacterial vaginosis and candidiasis infection among a cohort of women in the United States. Obstet Gynecol. 2013;121(4):773-780.

26. Bryant R. Acute and Chronic Wounds: Nursing Management. St Louis: Mosby; 1992.

27. Adam R. Skin care of the diaper area. Pediatr Dermatol. 2008;25(4): $427-433$.

28. Wolf G, Höger PH. Hypoallergenic and non-toxic emollient therapies for children. J Dtsch Dermatol Ges. 2009;7(1):50-60.

29. Larner J, Matar H, Goldman VS, Chilcot RP. Development of a cumulative irritation model for incontinence-associated dermatitis. Arch Dermatol Res. 2015;307:39-48.

30. Gray M, Black JM, Baharestani MM, et al. Moisture-associated skin damage: overview and pathophysiology. J Wound Ostomy Continence Nurs. 2011;38(3):233-241.

31. Bornstein J, Sideri M, Tatti S, Walker P, Prendiville W, Haefner HK; Nomenclature Committee of International Federation for Cervical Pathology and Colposcopy. 2011 terminology of the vulva of the international federation for cervical pathology and colposcopy. J Low Genit Tract Dis. 2012;16:290-295. 


\section{Publish your work in this journal}

Clinical, Cosmetic and Investigational Dermatology is an international, peer-reviewed, open access, online journal that focuses on the latest clinical and experimental research in all aspects of skin disease and cosmetic interventions. All areas of dermatology will be covered; contributions will be welcomed from all clinicians and

basic science researchers globally. This journal is indexed on CAS.

The manuscript management system is completely online and includes a very quick and fair peer-review system, which is all easy to use. Visit http://www.dovepress.com/testimonials.php to read real quotes from published authors.

Submit your manuscript here: http://www.dovepress.com/clinical-cosmetic-and-investigational-dermatology-journal 